\title{
Respiratory symptoms and atopy in Aberdeen schoolchildren: evidence from two surveys 25 years apart
}

\author{
Titus K Ninan, George Russell
}

\begin{abstract}
Objective-To estimate changes in the prevalence of respiratory symptoms and the reported diagnoses of asthma, eczema, and hay fever in primary school children in Aberdeen between 1964 and 1989.

Design-Determination of incidence prevalence and prevalence from survey data.

Setting-Aberdeen, Scotland.

Participants - 2743 primary school children (aged 8-13) from 1964 and 3942 from 1989.
\end{abstract}

Main outcome measures-Survey data on whether, according to the parent or guardian, the child wheezed or was troubled with shortness of breath; the number of episodes of breathlessness in the past year; and whether asthma, eczema, or hay fever had ever been diagnosed.

Results-Questionnaires were completed by the parents of 2510 children in 1964 and 3403 children in 1989. The prevalence of wheeze rose from $10.4 \%$ in 1964 to $19.8 \%$ in 1989 , and the prevalence of episodes of shortness of breath increased from $5 \cdot 4 \%$ to $10 \cdot 0 \%$. In both surveys wheeze and shortness of breath were more prevalent in boys than in girls. The reported diagnosis of asthma rose from $4 \cdot 1 \%$ to $10 \cdot 2 \%$, hay fever from $3.2 \%$ to $11.9 \%$, and eczema from $5.3 \%$ to $12 \%$. The proportion of boys suffering from eczema rose from $47 \cdot 7 \%$ to $60 \cdot 0 \%$. Hay fever showed a similar increase, from $49.4 \%$ to $60.1 \%$, in boys over the 25 year period. Though the parents of a higher proportion of children with wheeze were aware of the diagnosis of asthma in 1989, because of the increased prevalence of wheeze the absolute number of parents of wheezy children who were not aware of a diagnosis of asthma increased from $7 \cdot 4 \%$ to $9.6 \%$ of the population studied.

Conclusion - The higher diagnosis rate for asthma is due not simply to changes in diagnostic fashion but reflects an increase over the past 25 years in the prevalence of respiratory symptoms, which in turn may reflect a more general change in the prevalence of atopy, the increase in which was particularly noticeable in boys. This increase explains some of the increase in hospital admission rates for children with asthma.

Department of Child

Health, University of Aberdeen, Aberdeen AB9 2ZD

Titus K Ninan, research fellow

Department of Medical Paediatrics, Royal Aberdeen Children's Hospital, Aberdeen AB9 2ZG

George Russell, consultant in medical paediatrics

Correspondence to: Dr Ninan.

$B M \mathcal{1} 1992 ; 304: 873-5$

\section{Introduction}

During the past three decades there has been a substantial increase in medical activity related to asthma in the United Kingdom ${ }^{1+}$ and elsewhere, ${ }^{5-7}$ which must reflect either changes in medical practice -in particular the use of diagnostic labels - or a change in the prevalence of severity of the disease.

In the 1960s it was common medical practice in the United Kingdom to distinguish between asthma and wheezy bronchitis, a term applied to childhood wheezing precipitated by upper respiratory tract infection. In 1969 it was shown that these two conditions were part of the same spectrum, ${ }^{8}$ although the distinction continued to be reported as recently as $1978 . .^{9}$ The prevalence of asthma in Tyneside schoolchildren was $11 \%$ in $1979,{ }^{10}$ an apparent increase over previously reported figures. When the figures for wheezy bronchitis are added to those for asthma, however, several previous studies produce remarkably similar results: Aberdeen $11 \cdot 5 \%$," Melbourne $11 \cdot 4 \%,{ }^{8}$ United Kingdom $12 \cdot 3 \% .{ }^{9}$ Some of the apparent increase in the prevalence of childhood asthma therefore reflects changes in the use of diagnostic labels.

It is widely believed that the prevalence in asthma has increased in the United Kingdom, although the evidence is controversial. ${ }^{12}$ Hay and Higgenbottom, Anderson, and Hill et al have all pointed to the lack of any consistent trend in the results from published surveys of the prevalence of asthma. ${ }^{12-14}$

Serial prevalence surveys conducted in the same areas with the same methodology are necessary. Hill et $a l^{15}$ estimated that the prevalence of asthma in Nottingham schoolchildren had increased by $48 \%$ between 1985 and 1988 and suggested that this was due to a change of diagnostic labelling. We are aware of two serial prevalence studies carried out in the same population at an interval of over 10 years. ${ }^{16}{ }^{17}$ Mitchell found that the prevalence of reported asthma had increased from $7 \cdot 1 \%$ in 1969 to $13.5 \%$ in $1982 .{ }^{16}$ More recently Burr et al reported increases between 1973 and 1988 in the prevalence of wheezing $(17 \cdot 0 \%$ to $22 \cdot 3 \%)$ and asthma $(5 \cdot 5 \%$ to $12 \%)$ in 12 year old children attending schools in south Wales. ${ }^{17}$

Childhood asthma is commonly part of more general atopy. If there has been a true increase in the prevalence of wheeze or asthma, or both, it would be interesting to know if this reflects a general increase in the prevalence of atopy or if asthma alone was involved. We therefore studied the prevalence of respiratory symptoms and the diagnosis rate of other atopic conditions (eczema and hay fever) reported in two studies carried out in 1964 and 1989 in the city of Aberdeen using identical or virtually identical questions.

\section{Materials and methods}

In both studies the subjects were children aged from 8 to 13 years attending primary schools in Aberdeen. The questionnaires were administered to the parents or guardians of the children.

In 1964 information regarding respiratory symptoms and the diagnosis of asthma and other atopic diseases was collected as part of a large medicosociological survey conducted under the auspices of the Medical Research Council's medical sociology unit based in Aberdeen. The questionnaire was administered in the children's homes by trained interviewers and consisted of a total of 558 items, including numerous complex sociologically oriented questions. There were 30 simply worded medical questions including items on hospital admissions, clinic visits, atopic diseases, and common childhood symptoms. These responses were elicited by listing individual symptoms and diagnoses. Of 2743 children selected for interview, $2511(91 \cdot 5 \%)$ agreed to participate; details of 2510 children are available. For the present study we analysed only the results of those questions relating to respiratory and allergic symptoms and diagnoses. The comparisons presented in this paper are based on the unpublished 
results of the questionnaire and not on the subsequent clinical follow up study of Dawson et al. ${ }^{1}$

In 1989 permission was obtained from the director of education to approach the head teachers of 34 primary schools in Aberdeen to allow us to distribute a questionnaire restricted to items on respiratory symptoms and the reported diagnosis of asthma, hay fever, and eczema. The questionnaire was distributed by the class teacher to the parents or guardians of 3942 children and included a brief explanatory letter and a return envelope. The questionnaires were collected at the end of the week in which they were distributed; up to two reminders were sent. In all, $3403(85 \cdot 3 \%)$ of the questionnaires were completed.

The reported diagnosis of asthma, eczema, and hay fever were obtained using identical questions. To assess the clinical impact of wheeze, identical questions on the occurrence and frequency of episodes of shortness of breath were included in both studies.

The question on wheeze was modified in 1989. In 1964 the question was, "Has your child had a wheezy chest? If yes is it with a cold, sometimes without a cold or not known when?" In 1989 the question was, "Has your child had a wheezy chest in the last three years? If yes are the episodes of wheeze less than once every three months or more often than once every three months in the last year?"

Data were analysed using the SPSSX package on the University of Aberdeen's mainframe computer and confidence intervals were then calculated on a microcomputer. ${ }^{18}$

TABLE I-Changes in the prevalence of respiratory symptoms in primary school children, Aberdeen. Figures are numbers (percentages) unless otherwise stated

\begin{tabular}{|c|c|c|c|c|c|c|c|}
\hline & \multicolumn{3}{|c|}{1964 Survey } & \multicolumn{3}{|c|}{1989 Survey } & \multirow{2}{*}{$\begin{array}{c}\text { Relative risk } \\
\text { (95\% confidence } \\
\text { interval) }\end{array}$} \\
\hline & $\begin{array}{c}\text { Boys } \\
(n=1257)\end{array}$ & $\underset{(n=1253)}{\text { Girls }}$ & $\begin{array}{c}\text { Total } \\
(\mathbf{n}=2510)\end{array}$ & $\begin{array}{c}\text { Boys } \\
(\mathrm{n}=1746)\end{array}$ & $\begin{array}{c}\text { Girls } \\
(n=1644)\end{array}$ & $\begin{array}{c}\text { Total } \\
(n=3403)^{\star}\end{array}$ & \\
\hline \multirow{2}{*}{$\begin{array}{l}\text { Wheeze } \\
\text { Shortness of } \\
\text { breath }\end{array}$} & $163(6 \cdot 5)$ & $98(3 \cdot 9)$ & $261(10 \cdot 4)$ & 396 & 279 & $(19 \cdot 8)$ & $1.91(1.67$ to $2 \cdot 18)$ \\
\hline & $84(3 \cdot 3)$ & $52(2 \cdot 0)$ & $136(5 \cdot 4)$ & 207 & 134 & $(10 \cdot 0)$ & $1.85(1.53$ to 2.24$)$ \\
\hline
\end{tabular}

$\star$ Sex of 13 children was not identified on questionnaire.

TABLE II-Frequency of attacks of shortness of breath per year. Figures are numbers (percentages) unless otherwise stated

\begin{tabular}{|c|c|c|c|c|c|c|c|}
\hline & \multicolumn{3}{|c|}{1964 Survey } & \multicolumn{3}{|c|}{1989 Survey } & \multirow{2}{*}{$\begin{array}{l}\text { Relative risk } \\
\text { (95\% confidence } \\
\text { interval) }\end{array}$} \\
\hline & $\begin{array}{c}\text { Boys } \\
(\mathrm{n}=1257)\end{array}$ & $\underset{(\mathbf{n}=1253)}{\text { Girls }}$ & $\begin{array}{c}\text { Total } \\
(\mathbf{n}=2510)\end{array}$ & $\begin{array}{c}\text { Boys } \\
(n=1746)\end{array}$ & $\begin{array}{c}\text { Girls } \\
(n=1644)\end{array}$ & $\begin{array}{c}\text { Total } \\
(\mathrm{n}=3403)^{\star}\end{array}$ & \\
\hline 1-3 Ep & $23(0 \cdot 9)$ & $13(0 \cdot 5)$ & $36(1.4)$ & $69(2 \cdot 0)$ & $50(1 \cdot 4)$ & $119(3 \cdot 4)$ & 2.44 (1.69 to 3.5 \\
\hline 4-5 Episodes & $29(1 \cdot 2)$ & $14(0.5)$ & $43(1 \cdot 7)$ & $66(1.9)$ & $34(1 \cdot 0)$ & $100(2.9)$ & $1.72(1.20$ to 2.44$)$ \\
\hline$>5$ Episodes & $32(1 \cdot 3)$ & $25(1.0)$ & $57(2 \cdot 3)$ & $72(2 \cdot 1)$ & $50(1 \cdot 4)$ & $122(3.5)$ & $1.58(1.16$ to 2.15$)$ \\
\hline
\end{tabular}

^Sex of 13 children was not identified on questionnaire.

TABLE III-Changes in the prevalence of diagnosis of atopic conditions known to parents. Figures are numbers (percentages) unless otherwise stated

\begin{tabular}{|c|c|c|c|c|c|c|c|}
\hline & \multicolumn{3}{|c|}{1964 Survey } & \multicolumn{3}{|c|}{1989 Survey } & \multirow{2}{*}{$\begin{array}{c}\text { Relative risk } \\
\text { (95\% confidence } \\
\text { interval) }\end{array}$} \\
\hline & $\begin{array}{c}\text { Boys } \\
(n=1257)\end{array}$ & $\underset{(n=1253)}{\text { Girls }}$ & $\begin{array}{c}\text { Total } \\
(\mathbf{n}=2510)\end{array}$ & $\begin{array}{c}\text { Boys } \\
(n=1746)\end{array}$ & $\begin{array}{c}\text { Girls } \\
(n=1644)\end{array}$ & $\begin{array}{c}\text { Total } \\
(\mathrm{n}=3403)^{\star}\end{array}$ & \\
\hline & $71(2 \cdot 8)$ & $33(1 \cdot 3)$ & $104(4 \cdot 1)$ & $226(6 \cdot 6)$ & $121(3 \cdot 8)$ & $337(10 \cdot 2)$ & $1.75(1.40$ to 2.19$)$ \\
\hline Eczema & $63(2 \cdot 5)$ & $69(2 \cdot 8)$ & $132(5 \cdot 3)$ & $246(7 \cdot 2)$ & $163(4 \cdot 6)$ & $409(12 \cdot 0)$ & $2.33(1.93$ to 2.82$)$ \\
\hline Hay fever & $40(1 \cdot 6)$ & $41(1 \cdot 6)$ & $81(3 \cdot 2)$ & $246(7 \cdot 2)$ & $159(4 \cdot 7)$ & $405(11.9)$ & $3.70(2.93$ to 4.67$)$ \\
\hline
\end{tabular}

^Sex of 13 children was not identified on questionnaire.

TABLE IV-Diagnosis of asthma related to wheeze and shortness of breath

\begin{tabular}{|c|c|c|c|c|c|}
\hline & \multicolumn{2}{|c|}{1964 Survey $(n=2510)$} & \multicolumn{2}{|c|}{1989 Survey $(n=3403)$} & \multirow[b]{2}{*}{$\begin{array}{c}\text { Relative risk } \\
\text { (95\% confidence } \\
\text { interval) }\end{array}$} \\
\hline & $\begin{array}{l}\text { No (\%) of children } \\
\text { with symptoms }\end{array}$ & $\begin{array}{l}\text { No }(\%) \text { of parents } \\
\text { knowing asthma } \\
\text { diagnosis }\end{array}$ & $\begin{array}{l}\text { No }(\%) \text { of children } \\
\text { with symptoms }\end{array}$ & $\begin{array}{l}\text { No (\%) of parents } \\
\text { knowing asthma } \\
\text { diagnosis }\end{array}$ & \\
\hline Wheeze & $261(10 \cdot 4)$ & $73(27 \cdot 9)$ & $675(19 \cdot 8)$ & $331(49 \cdot 0)$ & $1.51(1.21$ to 1.88$)$ \\
\hline \multicolumn{6}{|c|}{ No of episodes of shortness of breath per year } \\
\hline $1-3$ & $36(1 \cdot 4)$ & $10(27 \cdot 8)$ & $119(3 \cdot 5)$ & $82(68 \cdot 9)$ & $1.88(1.06$ to 3.33$)$ \\
\hline $4-5$ & $43(1 \cdot 7)$ & $17(39 \cdot 5)$ & $100(2 \cdot 9)$ & $72(72 \cdot 0)$ & $1.48(6.95$ to $2 \cdot 29)$ \\
\hline$>5$ & $57(2 \cdot 3)$ & $30(52 \cdot 6)$ & $122(3 \cdot 6)$ & $108(88 \cdot 5)$ & $1.36(0.99$ to 1.88$)$ \\
\hline
\end{tabular}

\section{Results}

Of 3942 children identified from school registers as eligible for the survey, completed questionnaires were returned by the parents of 1746 boys, 1644 girls and 13 children whose parents for reasons of confidentiality chose not to complete the identification data in the questionnaire. Results for the total population are therefore based on 3403 returns, whereas when sex differences are compared the population is 3390 .

The overall prevalence of wheeze increased from $10.4 \%$ in 1964 to $19.8 \%$ in 1989 (table I). In both surveys wheeze was more prevalent in boys than girls. The prevalence of attacks of shortness of breath (table II) also increased between 1964 and 1989, the male to female ratio remaining similar. The increase was greater for less frequent than for more frequent attacks.

A diagnosis of asthma was reported by about twice as many parents in 1989 as in 1964 (table III). In particular, parents reported the diagnosis of asthma in almost $90 \%$ of children with frequent episodes of shortness of breath (more than five episodes a year) compared with just over half in similar cases 25 years ago (table IV).

The number of reported diagnoses of eczema reported by parents doubled and hay fever roughly trebled between the two studies (table III). Whereas the rate of diagnosed asthma in boys and girls was similar in both surveys, the proportion of boys in whom diagnoses of eczema and hay fever had been made increased appreciably over the 25 year period, eczema from $47 \cdot 7 \%$ to $60.0 \%$ and hay fever from $49 \cdot 4 \%$ to $60 \cdot 1 \%$.

\section{Discussion}

\section{METHODOLOGY}

Valid comparisons can be made between the 1964 and 1989 results despite differences in methodology. The length and complexity of the 1964 questionnaire fully justified the use of trained interviewers. In 1989 we confined our inquiries to simple questions on respiratory and allergic symptoms and diagnoses, and it was considered reasonable for our brief questionnaire to be sent out through the schools. Given the simplicity of the questions in both studies, it seems inherently unlikely that the difference in method of application could have had much impact on the responses. It is therefore unlikely that the differences in the findings could be attributable to changes in methodology because of the large increases that we observed in the prevalence of reported symptoms and diagnoses. Our modification to the question on wheeze was designed to identify those children in whom wheeze was a current, or at least a recent, problem; it would be expected to underestimate rather than exaggerate any increase in the prevalence of wheeze reported by the parents.

The belief that the prevalence of asthma is increasing is based largely on the results of studies in which there has been no consistency in the method of obtaining information, the questions asked, the ages of the children, the size and type of sample, the definition of asthma, or the locality in which the studies have been performed. Most of these problems have been addressed in the present investigation: both studies were based on information obtained by questionnaire, including the same (or very similar) questions; both questionnaires were targeted at a population of primary school children of similar ages living in the same city; specific inquiry was made about symptoms as well as reported diagnosis of asthma; in 1989 the questionnaires were distributed only in schools lying within the city boundaries as they existed in 1964 . 


\section{ASTHMA AND WHEEZE}

Burr $e t a l$ and Mitchell et al carried out serial surveys in the same populations and found that the prevalence of asthma had risen from $4 \cdot 2 \%$ to $9 \cdot 1 \%$ over 15 years $^{15}$ and from $7 \cdot 1 \%$ to $13 \cdot 5 \%$ over 13 years. ${ }^{16}$ In Aberdeen the prevalence of wheeze increased from $10 \cdot 4 \%$ to $19.8 \%$ between the two studies.

There are many possible reasons why wheeze might be commoner in 1989 than in 1964 . With the arrival of the oil industry, Aberdeen has become much more affluent in the past quarter century, and increased traffic fumes have replaced coal fire smoke as the major atmospheric pollutant. Increasing affluence has also resulted in a higher proportion of centrally heated, double glazed homes providing ideal warm humid conditions for the house dust mite (Dermatophagoides pteronyssinus). ${ }^{19}$ The chemical industry does not figure largely as a source of atmospheric pollution in Aberdeen, although in a small town surrounded by farming countryside, residents of Aberdeen are probably exposed to their fair share of agrochemical pollution.

Of 261 children in whom wheeze was reported in 1964 , a diagnosis of asthma was known to the parents in 73 instances $(28 \%)$ and of a diagnosis of bronchitis was known in $47(18 \%)$, leaving 141 parents (54\%) with no knowledge of any diagnosis. In contrast, a diagnosis of asthma was known in 331 (49\%) of the 675 wheezing children in 1989. This does not necessarily mean that the diagnosis of asthma is being made in a higher proportion of children with wheeze; it may simply mean that general practitioners are being more open in revealing their diagnosis to the parents. It is reassuring that in those children with the most frequent episodes of shortness of breath, the diagnosis rate for asthma has risen from just over half to almost $90 \%$, a finding which suggests that an appropriate diagnosis is being offered to virtually all of those children most seriously affected by asthma.

\section{ECZEMA}

The reported prevalence of eczema increased from $5.3 \%$ in 1964 to $12 \%$ in 1989 . This increase is similar to increases reported elsewhere. ${ }^{2021}$ Reasons for the increase in the prevalence of eczema might include the decline in breast feeding, the substitution in the mid1970s of spray dried infant milk formulas for roller dried (and less allergenic) formulas, the earlier introduction of weaning foods, and the widespread use of food additives, which might also be ingested indirectly through breast milk. ${ }^{22} 23$

\section{HAY FEVER}

The reported prevalence of hay fever has roughly trebled in the past 25 years. The magnitude of the increase and the similar increase in the prevalence of asthma and eczema support the idea that this represents a true increase in the prevalence of hay fever. Fleming et al came to a similar conclusion after examining the prevalence of hay fever in 1970-1 and 1980-1 on the basis of the national morbidity surveys in general practice. ${ }^{2}$ There is no evidence that pollen counts are increasing, and any explanation for the increase in hay fever is likely to focus on early allergenic exposure in general rather than on pollen exposure in particular.

\section{Conclusion}

This survey was undertaken primarily to see whether the prevalence of respiratory symptoms and reported diagnosis of atopic diseases had changed since a similar survey was done 25 years ago. Although no attempt was made to define asthma, it is the commonest cause of recurrent wheeze in childhood; the proportion of parents reporting wheeze in their children has approximately doubled in the past 25 years. The rise in the prevalence of reported asthma cannot be attributed solely to a change in diagnostic fashion because the prevalence in the primary school population of wheezing not diagnosed as asthma increased in the past 25 years from $7 \cdot 5 \%$ to $9 \cdot 8 \%$.

There was no evidence from this study that asthma is increasing in severity, despite reports of apparently disproportionate increases in hospital admissions for childhood asthma. ${ }^{15-7}$ Although the number of families reporting episodes of breathlessness increased at all levels of frequency, the increase was proportionately greatest for those with one to three attacks a year $(143 \%)$ and least for those with more than five attacks $(52 \%)$.

The prevalence of other atopic disease showed increases similar to those seen for wheeze and asthma. The increased prevalence of wheeze and of asthma may therefore reflect an increase in the prevalence of all forms of atopy in children, and any explanation for the increase in wheeze and asthma is likely to involve an explanation for the increases in eczema and hay fever.

We thank Daphne Russell and John Lemon for statistical and computing advice and Dr Blanche Dawson, Professor $\mathbf{R}$ G Mitchell, and David Oldman for information regarding the 1964 survey. Financial support from Astra Pharmaceuticals, Allen and Hanburys, and the National Asthma Campaign is gratefully acknowledged.

1 Anderson HR. Increase in hospital admissions for childhood asthma: trends in referral, severity and readmissions from 1970 to 1985 in a health region of the United Kingdom. Thorax 1989;44:614-9.

2 Fleming DM, Crombie DL. Prevalence of asthma and hay fever in England and Wales. BMF 1987;294:279-83.

3 Burney PJL. Asthma mortality in England and Wales. Evidence for a further increase, 1974-1984. Lancet 1986;ii:323-6.

4 Charleton JRH, Velez R. Some international comparisons of mortality amenable to medical intervention. $B M 7$ 1986;292:295-301.

5 Mitchell EA, Cutler DR. Paediatric admissions to Auckland hospital for asthma from 1970-1980. N Z Med f 1984;97:67-70.

6 Halfon N, Newacheck PW. Trends in the hospitalization for acute childhood asthma. Am F Public Health 1986;76:1308-11.

7 Bauman A, Lyle D, Taylor L, Thomson P. The use of medical records in epidemiology: a case study using asthma hospitalization in New South Wales, 1979-86. Australian Medical Records fournal 1990;20:105-15.

8 Williams HE, McNicol KN. Prevalence, natural history and relationship of wheezy bronchitis in children: an epidemiological study. BMF 1969;iv: $321-5$

9 Peckham C, Butler N. A national study of asthma in childhood. 7 Epidemiol Community Health 1978;32:79-85.

10 Lee DA, Winslow NR, Speight ANP, Hey EN. Prevalence and spectrum of asthma in childhood. BMJ 1983;286: 1256-8.

11 Dawson BM, Horobin G, Illsley R, Mitchell RG. A survey of childhood asthma in Aberdeen. Lancet 1969; i:827-30.

12 Anderson HR. Is the prevalence of asthma changing? Arch Dis Child 1989;64:172-5.

13 Hay JFC, Higgenbottom TW. Has the management of asthma improved? Lancet 1987;ii:609-11.

14 Hill RA, Standen PJ, Tattersfield AE. Asthma, wheezing and school absences in primary schools. Arch Dis Child 1989;64:246-51

15 Hill RA, Williams J, Tattersfield A, Britton J. Change in use of asthma as a diagnostic label for wheezing illnesses in schoolchildren. BMF 1989;299:898. 16 Mitchell EA. Increasing prevalence of asthma in children. NZ Med f 1983;96:463-4.

17 Burr ML, Butland BK, King S, Vaughan Williams E. Changes in asthma prevalence: two surveys fifteen years apart. Arch Dis Child 1989;96:1452-6. 18 Gardner MJ, Altman DG. Statistics with confidence. London: British Medical Journal, 1989.

19 Korsgaard J. Preventive measures in house dust mite allergy. Am Rev Respir Dis $1982 ; 125: 80-4$

20 Taylor B, Wardsworth J, Wardsworth M, Peckham C. Changes in the reported prevalence of childhood eczema since the 1939-45 war. Lancet 1984;i: $465-71$.

21 Max-Kjellman NJ. Atopic disease in seven year old children. Acta Pediatr Scand 1977;665:465-71.

22 Gerrard WJ, Shennan M. Sensitization to substances in breast milk: recognition, management and significance. Ann Allergy 1983;51:300-2.

23 Reinhardt MC, Paganelli R, Levinski RJ. Intestinal antigen handling at mucosal surfaces in health and disease: human and experimental studies. Ann Allergy 1983;51:311-4.

(Accepted 10 February 1992) 